\title{
La fabricación de un mito: el terremoto de 1687 y la ruina de los cultivos de trigo en el Perú
}

\author{
Pablo E. Pérez-Mallaína \\ Departamento de Historia de América \\ Facultad de Geografía e Historia \\ Universidad de Sevilla
}

Uno de los temas más polémicos en la historiografía sobre el Perú colonial gira en torno a la determinación de si el gran movimiento sísmico que destrozó Lima el 20 de octubre de 1687 fue también el causante de la ruina de la producción de trigo en los valles de la costa central. La mayoría de los cronistas y de los investigadores contemporáneos apoyan la relación de causa-efecto entre ambos fenómenos. El presente artículo, utilizando documentación inédita del Archivo General de Indias de Sevilla, pretende demostrar que dicha relación fue producto de una invención posterior e interesada y, al mismo tiempo, reflexiona sobre cómo, cuándo y por qué se creó este verdadero mito historiográfico.

Muchos de los cronistas y testigos de la vida limeña en el siglo XVIII y una buena parte de la historiografía que sobre el Perú se ha producido en los siglos XIX y XX han contribuido a fabricar un mito, a dar vida a un verdadero monstruo: el del gran movimiento sísmico que, además de derribar las casas y hundir templos y palacios, envenena los campos e impide que la tierra de frutos.

Curiosamente, de los miles de terremotos de los que hay testimonio que han asolado el Perú, solo a uno, el acaecido el 20 de octubre de 1687, se le achacan tanta cantidad de males, e incluso hay algún autor que lo considera como una de las causas importantes para explicar la decadencia del virreinato peruano y el hecho de que dejara de ser la principal joya de la Corona española en América. ${ }^{1}$

Se supone que el seísmo en cuestión tuvo su epicentro en el mar a poca distancia de Cañete. Debido a su extraordinaria fuerza se le clasificó como el de mayor potencia de los sufridos hasta entonces por el virreinato. ${ }^{2}$

1 Céspedes del Castillo, G.: "Lima y Buenos Aires. Repercusiones económicas y políticas de la creación del virreinato del Plata”, Anuario de Estudios Americanos, tomo III, Sevilla, 1946, págs. 677-874. En esta obra, el gran historiador sevillano contrapone un estado casi idílico de la agricultura de los valles costeros en el siglo XVII, que define como “...oasis donde nada falta...”, con la ruina que sobrevino tras el seísmo de 1687. Véanse págs. 721-722.

2 Giesecke, A y E. Silgado: Terremotos en el Perú, Lima, 1981, págs. 65-67. 
Causó gravísimos daños en Lima y El Callao, arrasando Pisco, Ica y Cañete. En los Andes, Huarochirí y Arequipa resultaron muy afectadas. Ya en el Cuzco sus sacudidas no produjeron daños, pero hay testimonios que indican que incluso en la lejana Concepción, en el reino de Chile, se llegaron a sentir sus efectos. ${ }^{3}$

Con todo, a pesar de la virulencia de sus sacudidas y de la cantidad de edificios, vidas y haciendas que se llevó consigo, esta catástrofe es especialmente recordada por que, según la creencia más extendida, terminó con los cultivos de trigo que se realizaban en los valles cercanos a Lima, inutilizando los campos de manera permanente para producir este cereal y favoreciendo que, a partir de entonces, los limeños dependiesen para su abastecimiento de grano importado procedente de Chile.

Pues bien, este artículo pretende derribar este mito a la luz de documentación inédita procedente del Archivo General de Indias de Sevilla. Gracias a ella resulta evidente que los rigurosos contemporáneos de la catástrofe nunca establecieron que existiese una relación de causa-efecto entre la crisis cerealera y el terremoto de 1687 y que todo se trató de una invención posterior, aparecida a lo largo del siglo XVIII. Por otra parte, el presente trabajo desea también formular la hipótesis de cómo, cuándo y por qué surgió esta verdadera calumnia ecológica. En el fondo se trata de un intento de enfrentarse a ese desafío de las actuales formas de hacer historia que ponen su énfasis, no ya en los hechos y ni siquiera en cómo fueron percibidos, sino en la manera en que fueron fabricados para pasarlos como evidencias a las generaciones posteriores. Sirvan estas líneas como una pequeña contribución a eso que se viene llamando la historia de "la construcción de la memoria". ${ }^{4}$

$$
* * *
$$

Uno de los más brillantes historiadores peruanos contemporáneos, Alberto Flores Galindo, ratifica en el libro que le dedicó a la sociedad limeña del XVIII que la cuestión de si el terremoto causó o dejó de causar la crisis agrícola es, en efecto, un tema recurrente en la historiografía

3 Archivo General de Indias (en adelante AGI), Lima, 304. El arzobispo de Lima, don Melchor Liñán y Cisneros, al rey, Late (a legua y media de Lima), 3 de febrero de 1687. págs. 77-78.

4 Duby, G.: Diálogos sobre la Historia. Conversaciones con Guy Lardreau, Madrid, 1988, 
peruanista. Tan trillado está el asunto que uno de los epígrafes de su obra lo tituló: "La cuestión del trigo: una vieja polémica". 5 Se trata de un resumen actualizado y completo, que me exime de realizar aquí una puesta al día del tema. Baste recordar que se refiere a los más destacados cronistas e historiadores que han defendido la relación más o menos directa entre ambos fenómenos: Hipólito Unanue, José María Pando, Guillermo Céspedes del Castillo, Óscar Febres Villaroel, Demetrio Ramos Pérez, etc. Del mismo modo, relaciona los nombre de algunas "excepciones" a esta tendencia generalizada como fueron, entre otros, Manuel Mendiburu en el siglo XIX o Rugiero Romano en el XX.

Realmente, la cuestión ha estado presente en los tres siglos siguientes a que, supuestamente, se produjeran los hechos: la trataron gobernantes ilustrados del siglo XVIII, como el oidor don Pedro José Bravo de Lagunas y Castilla; ${ }^{6}$ ha pasado por esa voz de la memoria popular decimonónica que es Ricardo Palma, el cual la recoge en una de sus "tradiciones"; 7 y ha llevado a que ingenieros agrónomos y otros técnicos del siglo XX se vean obligados a dar su parecer al respecto. ${ }^{8}$

Flores Galindo, después de valorar todos los antecedentes y aplicando el sentido común, expone sus más que razonables dudas de que el seísmo de 1687 fuese el "culpable" de la ruina triguera y lo hace a través de unas preguntas muy sensatas. ¿Por qué, si en el Perú se pueden contar una veintena de terremotos tan formidables como aquel e incluso algunos de mayor intensidad (como el de 1746), ninguno de ellos causó mal a la agricultura? ¿Cómo puede un temblor provocar daños tan catastróficos y, sobre todo, tan prolongados??

Para este autor las verdaderas razones de la preponderancia del trigo chileno hay que buscarlas en explicaciones de índole fundamentalmente económica, basadas en la mayor productividad y menor precio del cereal

5 Flores Galindo: La ciudad sumergida. Aristocracia y Plebe en Lima, 1760-1830, Lima, 1991, págs. 23-28.

6 Bravo de Lagunas y Castilla, P.J.: "Voto consultivo que ofrece al Exmo. Sr. don José Antonio Manso de Velasco...el Dr. Don Pedro José Bravo de Lagunas y Castilla...”, Lima, 1761.

7 Palma, R.: Tradiciones peruanas completas, Madrid, 1968. En la "tradición" titulada: "Cortar el revesino" y que se dedica al tiempo del virrey duque de la Palata, el gran escritor peruano se refiere a que "...por consecuencia del terremoto de 1687 perdiéronse las cosechas de los valles inmediatos a Lima...”, pág. 464.

8 Flores Galindo, A.: La ciudad sumergida..., pág, 27. En esta obra se recoge la opinión de los ingenieros Teodoro Boza y Marino Loli, el último de los cuales fue jefe del programa de cereales de la Universidad Nacional Agraria del Perú.

9 Ibídem, pág. 24. 
chileno. A ello se deben sumar los intereses de los poderosos gremios de navieros y panaderos limeños, que estaban fuertemente decididos a mantener este lucrativo negocio y lograron imponerse a los menos organizados hacendados de los valles costeros.

¿Cuáles son entonces las razones -sigue preguntándose Flores Galindo- para que de una forma tan mayoritaria se haya venido manteniendo la relación entre el seísmo y la esterilidad de las tierras? En el fondo se trata de una cuestión de fuentes o, más bien, de falta de ellas. Todo se basa en opiniones y juicios de personas que escribieron en fechas muy posteriores a los hechos o lecturas precipitadas e incompletas de contemporáneos. Y concluye: "Escasean los testimonios directos. La suma de fuentes tan deleznables, por muy abundantes que sean, no avala ningún argumento". ${ }^{10}$

Por mi parte suscribo al cien por cien las opiniones del historiador peruano, y en mayor medida si se tiene en cuenta que ahora sí disponemos de esos "testimonios directos" que él echaba en falta.

$$
* * *
$$

Esta nueva fuente de información la proporciona un grueso expediente que se conserva en la sección de Escribanía de Cámara del Archivo General de Indias de Sevilla. Los acontecimientos reflejados en estos documentos ocurren entre los años 1687 y 1709 y tienen un denominador común: la petición dirigida a la Corona por los hacendados de los valles cercanos a Lima para que, en vista de las repetidas catástrofes que estaban sufriendo, se les concediese algún tipo de compensación económica. ${ }^{11}$

Los hacendados de Lima, al pedir beneficios particulares, tenían a la vista un precedente general. A raíz del terremoto de 1687, la Corona, por Real Cédula de 13 de abril de 1689, había concedido al conjunto de la ciudad de Lima la exención de pagar alcabala durante cinco años, concretamente entre 1690 y 1695 . No era mal regalo, pues suponía un ahorro cal-

10 Ibídem, pág. 25.

11 AGI, Escribanía de Cámara, 519-A. "Testimonio de los autos que siguen los hacendados y labradores de Indias en la Real Audiencia de Lima sobre la esterilidad de frutos y demás que contiene su demanda y de las reales cédulas, instrumentos, pareceres, informes, prueba y sentencia que se ha dado, y de lo demás sustancial, con relación de lo más conveniente y súplica que se ha interpuesto". El expediente culmina con el auto del Consejo de Indias de 20 de noviembre de 1709, en el cual se ratifica la sentencia dada por la Audiencia de Lima el 17 de mayo de 1707. 
culado en 347.000 pesos en total. ${ }^{12}$ Sin embargo, antes de que concluyera el plazo en que todos los ciudadanos estaban libres de pagar aquel derecho, concretamente en 1692, una nueva desgracia se abatió sobre una parte concreta de los vecinos: los campos se vieron aquejados por un proceso creciente de esterilidad que afectó sobre todo a los cultivos de trigo y en menor medida a los de caña de azúcar y alfalfa.

Como puede comprenderse, se trata de un hecho clave para nuestra argumentación: ¡hasta el año de 1692, es decir, cinco años después de que se produjese el gran seísmo, los hacendados no se quejan de la productividad de sus tierras! Es más, por informaciones posteriores sabemos que algunas de las cosechas recogidas entre 1687 y 1692 fueron consideradas como excepcionalmente buenas. Pero no adelantemos acontecimientos y sigamos el curso que nos marcan los documentos.

Ante esta nueva desgracia que los atacaba en exclusiva, los hacendados se organizaron. Nombraron apoderados ante la Corte de Madrid para lograr convencer a las autoridades metropolitanas de que, una vez terminada en 1695 la exención general de pagar alcabalas, se les concediese a ellos una prórroga de este beneficio. Al mismo tiempo, pretendían conseguir algún tipo de rebaja en el pago de los censos que gravaban sus propiedades y de los que, en su mayor parte, eran beneficiarios distintas asociaciones de carácter religioso.

La presión ejercida ante el rey tuvo éxito y una Real Cédula fechada el 15 de febrero de 1699 ordenaba dos cosas: en primer lugar mandaba al virrey del Perú que informase sobre la conveniencia de ampliar la exención de alcabalas a los hacendados y, en segundo término, facultaba a la Real Audiencia de Lima para decidir si procedía moderar los intereses de los censos que pagaban los terratenientes.

El asunto de las alcabalas dependía enteramente de la voluntad de los gobernantes y por ello se solucionó con relativa rapidez: tras un informe del Real Acuerdo del virreinato peruano, el rey concedió a los limeños una rebaja muy sustancial en las alcabalas que habrían de pagar. Estas quedaron fijadas en 4.500 pesos anuales, cuando anteriormente los hacendados habían estado contribuyendo con hasta 14.000 pesos al año. ${ }^{13}$

12 AGI, Lima, 530. El Cabildo Eclesiástico de Lima al conde de la Monclova, Lima, 20 de abril de 1700 .

13 AGI, Lima, 407. El Real Acuerdo de Lima al rey, Lima, 11 de septiembre de 1700. Véase también: AGI, Escribanía de Cámara, 519-A. "Testimonio de los autos que siguen los hacendados y labradores...". Certificación de don Ignacio de Loyola, contador de las alcabalas, Lima, 17 de febrero de 1700 . 
Rebajar los censos resultó, sin embargo, un asunto mucho más complejo que disminuir la alcabala. Ya no se trataba de una decisión que debían tomar exclusivamente las autoridades, sino de un conflicto entre dos sectores sociales privilegiados: los propietarios agrícolas y las instituciones religiosas, que eran los principales y casi exclusivos beneficiarios de los censos. Los eclesiásticos debían ser oídos y por ello la cuestión dio lugar a un largo "pleito entre partes", desarrollado entre 1699 y 1709, que es el que nos sirve como principal fuente de información.

El conflicto legal dio comienzo con una petición realizada ante la Audiencia el 9 de noviembre de 1699 por Diego Esteban Berrocal, apoderado de los hacendados. En conjunto conforma una documentación sumamente rica y susceptible de ser utilizada por los historiadores desde varios puntos de vista.

En primer lugar, permite comprobar el funcionamiento de los grupos de presión, auténticos "lobbys", que se encargaban en Madrid de hacer llegar a buen puerto las peticiones de los grupos económicos y sociales de las colonias. Así, los poderes concedidos por los terratenientes limeños sufrieron una serie de delegaciones sucesivas y fueron pasando de unos apoderados a otros hasta que llegaron a personas bien colocados ante la Corte, normalmente secretarios de altos personajes, que tenían capacidad para influir sobre sus jefes y lograr que se expidiese tal o cual real cédula.

También los documentos son una buena forma de acercarnos a elementos de la mentalidad de los terratenientes limeños que, a lo largo de sus testimonios, nos dan su visión de cómo se enfrentan a la ruina y qué es lo que más les apena de la pobreza, la cual para ellos se simboliza, por ejemplo, en que sus mujeres no puedan lucir las joyas que les corresponden y distinguen de las demás féminas de peor condición.

Asimismo, el pleito muestra la tremenda fractura social existente entre una parte tan distinguida de la sociedad civil y el clero. Los terratenientes, molestos por la falta de solidaridad de los estamentos religiosos, que no accedían a bajar los censos en una época de tanta calamidad, calificarán la negativa de los eclesiásticos de "repugnante", "inicua", "injusta", "injuriosa" y propia de usureros. Ante esta avalancha de lindezas, deberá ser el propio arzobispo y antiguo virrey, don Melchor Liñán y Cisneros, el que tratará de defender la posición de su gremio indicando que, habida cuenta de su importantísimo ministerio, parecía lógico que los religiosos "se alimentasen del altar". ${ }^{14}$

14 AGI, Escribanía de Cámara, 519-A. Parecer del arzobispo don Melchor Liñán y Cisneros ante la Real Audiencia, Lima, 25 de octubre de 1704. 
La decisión final de la Audiencia se produjo en la sentencia de 17 de mayo de 1707 y la ratificó el consejo de Indias el 20 de septiembre de 1709. Ambas resoluciones dieron una respuesta positiva a las demandas de los labradores, ordenando rebajar los intereses de los censos de las haciendas trigueras del $5 \%$ al 2\%, y a sólo el 3\%, si además de trigo las tierras producían cualquier otra cosa. Fue la primera de una serie de auténticas desamortizaciones encubiertas de los bienes eclesiásticos que se iban a realizar en el Perú, aprovechando, precisamente, épocas de catástrofes naturales o de conflictos armados. ${ }^{15}$

Pero siendo todos esos asuntos de enorme trascendencia, lo más interesante para el tema que nos ocupa es que a lo largo del pleito quedó meridianamente claro que ninguno de los rigurosos contemporáneos del terremoto de 1687 establecieron la más mínima relación entre este seísmo y las perdidas de las cosechas de trigo que se sucedieron a partir del año de 1692.

Para nuestro propósito resulta especialmente útil una declaración de 27 testigos presentados por el apoderado de los terratenientes. La prueba testifical pretendía demostrar la agobiante situación económica por la que pasaban los hacendados. Los testigos están, por tanto, escogidos entre los propios dueños o arrendatarios de haciendas, a los que se añaden cuatro mayordomos o capataces. ${ }^{16} \mathrm{Ni}$ que decir tiene que el tenor de las preguntas refleja la opinión general del grupo de propietarios agrícolas, todos los cuales responden de la misma manera, refrendando las afirmaciones que estaban implícitas en el interrogatorio. En ese sentido, ya en la segunda pregunta queda absolutamente claro que los problemas agrícolas comenzaron en 1692 y no en 1687 y que las causas que los afectados estaban considerando tampoco tenían nada que ver con el movimiento sísmico. Este es el texto de la pregunta:

"Si saben que de 14 años a esta parte, desde el de seiscientos noventa y dos, hasta el presente, se ha padecido en las haciendas de campo de los contornos de esta ciudad,

15 Bauer, A.J.: "The Church in the Economy of Spanish America: Censos and Depósitos in the Eighteenth and Nineteenth Centuries", Hispanic American Historical Review, vol. 63, n. 4, Durham, 1983, págs. 707-733.

16 AGI, Escribanía de Cámara, 519-A. Prueba testifical fechada en Lima el 9 de enero de 1706. De los 23 propietarios o arrendatarios, 12 poseen grado de oficiales de milicias; 2 ostentan el rango de regidores perpetuos de Lima; 4 son presbíteros y a 5 se les caracteriza únicamente como "españoles". 
por accidente de los tiempos y por la fatalidad del influjo, una general y nunca vista esterilidad de frutos". ${ }^{17}$

Desde luego que había ruinas y destrozos achacables al temblor, pero estos se circunscribían a los daños que habían sufrido las casas de las haciendas, las cercas o las acequias, tal y como queda establecido en la décima pregunta que es sometida a los testigos:

"Si saben que desde el año de 87 se han continuado graves y terribles terremotos que han arruinado gravemente las casas de la ciudad que tienen dichos hacendados y [en] las de campo, sus oficinas para la habitación, ministerios de la labranza, las cercas, los caminos y acequias". ${ }^{18}$

Como ya hemos indicado, todos los testigos responden afirmativamente y deslindan perfectamente entre las consecuencias de los terremotos y las pérdidas agrícolas producidas por los "accidentes de los tiempos y la fatalidad de los influjos". Uno de los testigos es especialmente claro a este respecto. Se trata del capitán Juan de Sandoval, un hacendado de 55 años, vecino del valle de Late, el cual, respondiendo a la décima pregunta, en que debía comentar los daños del terremoto de 1687, decía lo siguiente:

“... Se ha seguido a los dueños de casas y chacras mucho perjuicio y daño y gasto que comúnmente ha ocasionado la calumnia (sic) de dichos temblores, siendo así que ha sido pérdida aparte a la esterilidad...." ${ }^{19}$

Queda pues meridianamente claro que los propios interesados consideraban que la pérdida de las cosechas era una desgracia "aparte" de las que producían los temblores. ¿Podrían tener los labradores alguna razón para mentir? No parece probable. Al fin y al cabo la Corona ya había concedido exenciones tributarias por el terremoto de 1687 y los hacendados podían haber usado esta circunstancia como precedente para sus nuevas reivindicaciones con respecto a los censos.

Pero es que, además, no sólo eran los hacendados los que distinguían entre terremotos y esterilidades. El virrey conde de la Monclova y el pleno de la Audiencia, reunidos en Real Acuerdo, expresaron al rey que la ruina de los campos era un hecho que no se había ocasionado antes del $1692 .^{20}$

17 Ibídem.

18 Ibídem.

19 Ibídem. de 1700 .

20 AGI, Lima, 407. El Real Acuerdo de la Audiencia de Lima al rey, Lima, 11 de septiembre 
Y para que no falte la opinión de ninguna autoridad de importancia, puede añadirse que el propio arzobispo, don Melchor Liñán de Cisneros, achacaba las perdidas de las cosechas a ".....accidente de los tiempos, fatalidad del influjo y epidemia..... . ${ }^{21}$

Hasta aquí hemos aportado opiniones y juicios de valor, pero es que la consulta, bastante más desapasionada, de las cuentas de los diezmos nos muestra que entre 1697 y 1692 se dieron algunas cosechas de trigo calificadas como realmente excepcionales.

Uno de los testigos presentados por los labradores fue el presbítero, licenciado Juan de Solano, que anteriormente había ejercido de "diezmero" en las propiedades de don Santiago de Urdanegui, uno de los más poderosos hacendados limeños de fines del siglo XVII. Pues bien, según el licenciado Solano, en el trienio 1688 a 1690 “.....recogió en abundancia el diezmo de trigo, cebada, maíz y frijol...”. ${ }^{22}$ Los principales beneficiarios de los diezmos, es decir, los miembros del Cabildo Eclesiástico de Lima, refrendaban esta información en un memorial dirigido al virrey conde de la Monclova, en el que reconocían que pocos años habían sido tan fructíferos para los diezmos como el periodo 1690-1691. ${ }^{23}$ Finalmente, el informe del secretario del cabildo Eclesiástico, especificaba que tras haberse ingresado 109.838 pesos por diezmos entre mayo de 1690 y abril de 1691, la recaudación bajó a tan sólo 46.944 pesos en el periodo 1692-1693.24

Como puede verse, las pruebas son abrumadoras, de tal manera que puede concluirse sin temor a error que los contemporáneos no establecieron ninguna relación causa-efecto entre el terremoto de 1687 y la crisis triguera que apareció a partir de 1692.

Cuando a los propios labradores se les interrogó por las causas que habían provocado la ruina de los campos, las respuestas fueron de lo más variadas y la propia amplitud de posibilidades demuestra que, en realidad, no sabían lo que estaba pasando. Así, muchos se refieren a las heladas; otros a la humedad llegada en mal momento: "garúas a destiempo"; y son frecuentes las referencias a diversas plagas animales tales como "la palo-

21 AGI, Escribanía de Cámara, 519-A. Parecer del arzobispo don Melchor Liñán y Cisneros ante la Audiencia, Lima, 25 de octubre de 1704.

22 Ibídem. Declaración del licenciado Juan de Solano, Lima, 9 de enero de 1706.

23 AGI, Lima, 530. El Cabildo Eclesiástico de Lima al conde de la Monclova, Lima, 20 de abril de 1700 .

24 AGI, Escribanía de Cámara, 519-A. "Testimonio de los autos que hacen los hacendados y labradores...”. Certificación dada por don Juan Manuel del Molino, secretario del Cabildo Eclesiástico y presentada ante la Audiencia por los hacendados limeños; sin fecha. 
milla", "el gusano" o ciertas "arañitas prietas". Junto a estos motivos concretos y comunes en el mundo de la agricultura, se aducen otras explicaciones más imprecisas como "epidemias del tiempo", "fatalidad del influjo y la intemperie”, y, ¡cómo no!, la omnipresente "voluntad de Dios" como última e inescrutable causa de la mayoría de las desgracias que acontecen a los seres humanos. Como ejemplo de respuesta sobre las causas de la esterilidad, puede escogerse la de uno de los mayordomos de hacienda llamado Nicolás Ortiz:

"Se quitó este testigo el sombrero a sacudir la garúa que hacía y vio mucha cantidad de arañitas prietas que parecían goterones de agua ... de que resultó hacer juicio que en las lluvias caía la peste a las sementeras ... por ser un caso irregular y que, conocidamente, las garúas fuera de su tiempo son apestadas para las sementeras". ${ }^{25}$

Desde la distancia que nos separa de los hechos, parece una empresa arriesgada que nosotros, ahora, nos aventuremos a encontrar una explicación única, rápida y sencilla para una crisis agrícola de fines del siglo XVII. Supongo que habremos de contentarnos con interpretaciones generales de carácter económico, basadas en las diferencias de productividad, de coste de mano de obra o de abaratamiento del transporte marítimo, como ya han apuntado varios autores, entre los que puede destacarse a Alberto Flores Galindo, apoyado posteriormente por Enrique Tandeter. ${ }^{26}$

Tal vez pueda añadirse que las tierras templadas de Chile presentaban unas condiciones naturales para el cultivo del trigo que, antes o después, terminarían dándole ventaja. Me pregunto si, con las limitaciones tecnológicas de los siglos XVI y XVII, empecinarse en plantar trigo en el Perú no constituyó un desafío demasiado fuerte contra la naturaleza. Una apuesta tan atrevida que, quizá, no sólo sea explicable por razones puramente económicas, pues no debe olvidarse que este cereal tenía, además de un valor en el mercado, un especial valor cultural para los españoles: los criollos peruanos se aventuraron a plantar trigo entre los trópicos porque, entre otras razones, el pan que fabricaban con él era considerado el alimento más adecuado para un hombre civilizado.

25 Ibídem. Testimonio del mayordomo Nicolás Ortiz, Lima, 9 de enero de 1706.

26 Tandeter, E.: "Población y economía en los Andes", Revista Andina, n 1, Cuzco, julio, 1995, págs. 7-42. En el fondo ésta es también la postura que defendió Demetrio Ramos, el cual hacía referencia a la existencia de una crisis de producción anterior al terremoto, la cual se precipitó cuando el seísmo rompió las acequias y encharcó los cultivos. Véase Ramos Pérez, D.: Trigo chileno, navieros del Callao y hacendados limeños entre la crisis agrícola del siglo XVII y la comercial de la primera mitad del siglo XVIII, Madrid, 1967. 
Eso al menos es lo que se desprende del testimonio de uno de los hacendados limeños, el capitán don Bartolomé Rodríguez de Pelaustán. Este veterano terrateniente se vio en la necesidad de explicar por qué durante la crisis agrícola habían muerto varios de sus colegas. Lo achacó a la pena por verse arruinados, $\mathrm{o}$ al hecho de estar mal nutridos por comer un alimento, como el maíz, propio de indios:

"Por no poder alcanzar muchas familias para el gasto del pan, se valían del maíz, de que resultó graves accidentes, por ser mantenimiento contra la naturaleza, en que no estaba[n] habituada[s]". ${ }^{27}$

$* * *$

¿Si los contemporáneos no establecieron relación alguna entre el seísmo y la crisis triguera, cuando y por qué se generó una idea tan persistente? Da la impresión que de manera explicita debió formularse a fines de la primera década del siglo XVIII. En ese sentido, cuando en 1708, el representante de los hacendados limeños apeló la sentencia de la Audiencia de Lima ante el Consejo, ${ }^{28}$ no hay nada en su memorial que permita entrever que ha nacido el mito del terremoto destructor de las cosechas. ${ }^{29}$ Sin embargo, cuando en el año 1713 el viajero francés Frezier visitó el Perú debió oír comentarios al respecto, que luego trasladó a la memoria de su viaje que publicó en 1732:

"Depuis le tremblement de 1678 (sic) la terre n'y produit pas du bled comme auparavant, c'est purquoi on trouve meilleur marché de la faire venir du Chily". ${ }^{30}$

Según Flores Galindo este es el primer comentario escrito que achaca la responsabilidad de la crisis agrícola al terremoto de $1687,{ }^{31}$ sin embargo hay que advertir que, a nivel de planteamiento teórico, la posibilidad de que

27 AGI, Escribanía de Cámara, 519-A. "Testimonio de los autos que hacen los hacendados y labradores...", declaración del capitán Bartolomé Rodríguez de Pelaustán, Lima, 9 de enero de 1706.

28 Aunque dicha sentencia les fue favorable, los terratenientes tenían la esperanza de una supresión total de los censos.

29 AGI, Escribanía de Cámara, 519-A. Memorial de Juan Bautista Munilla, apoderado de los hacendados limeños, enviado al fiscal del Consejo de Indias el 9 de agosto de 1708.

30 Frezier: Relation du voyage de la Mer du Sud aux côtes du Chilly et du Perou, fait les années 1712, 1713 et 1714...par Monsieur Frezier, ingenieur ordinaire du Roy, Paris, 1732.

31 Flores Galindo: La ciudad sumergida..., pág. 23. 
un terremoto pudiese envenenar las tierras era un hecho perfectamente admisible por la ciencia de la época. Los geógrafos grecolatinos explicaban los terremotos por la acción de gases nitrosos y sulfurosos que se producían en el interior de la tierra como resultado de combustiones espontáneas de materiales en contacto con el agua del mar o de cualquier río o lago subterráneo. Se pensaba en una reacción semejante a la que se produce cuando la cal viva entra en contacto con agua. Cuando estos "vientos venenosos" no encontraban salida, se producía un terremoto que provocaba numerosos escapes gaseosos. Si estos revertían a la tierra mezclados con las gotas de lluvia, los campos podían quedar infectados y estériles. ${ }^{32}$

Ahora bien, una cosa es creer en que algo es posible y otra afirmar que se ha producido en la realidad. Este trascendental paso se dio en el Perú a lo largo del siglo XVIII y, de hecho, para cuando se produjo el mayor y más dramático seísmo de la época colonial, el ocurrido el 28 de octubre de 1746 , todo el mundo creía y temía que los campos podían volver a quedar estériles.

El virrey que gobernaba el Perú a mediados del XVIII, don José Antonio Manso de Velasco, luego nombrado conde de Superunda, afirmaba en su memoria de gobierno que “...una de las más sensibles resultas del gran terremoto que arruinó [Lima] el año de 1687 fue la esterilidad que padecieron sus tierras...". ${ }^{33}$ Mientras que el arzobispo don Pedro Antonio Barroeta expresaba con toda claridad el temor de sus feligreses a que estos hechos se repitiesen e informaba al rey que en la ciudad existía el "concepto común" de que el trigo limeño estaba contaminado. ${ }^{34}$

El más destacado miembro de la ilustración criolla limeña de mediados del XVIII, José Eusebio de Llano Zapata, ${ }^{35}$ nos da una de las versiones más detalladas del miedo que tenían incluso los elementos más cultos de aquella sociedad a que las dramáticas consecuencias del terremoto de 1687 se repitieran tras el de 1746 :

32 Según la actual teoría de placas y aunque se admite que puedan producirse algunos escapes gaseosos a lo largo de un terremoto, no parece admisible que se llegue a la esterilización química de amplias porciones de terreno. Otra cosa distinta puede ocurrir con las erupciones volcánicas, que sí pueden dejar inutilizadas considerables extensiones de campos de cultivos. Véase: Moores, E.M y R.J. Twis: Tectonics, New York, 1995.

33 Manso de Velasco, J.A.: Relación que escribe el conde de Superunda..., en Fuentes, A. (editor): Memorias de los virreyes que han gobernado el Perú durante el tiempo del coloniaje español, El Callao, 1859, tomo IV, pág. 126.

34 AGI, Lima, 986. El arzobispo de Lima al rey, Lima, 26 de febrero de 1756.

35 Álvarez Brun, F.: "José Eusebio de Llano Zapata", Nueva Coronica, n. ${ }^{\circ}$ 1, Lima, 1963, págs. 33-101. 
"Creo que abiertas las oficinas subterráneas y poros con tan repetidos movimientos, saldrían ejércitos de exhalaciones (sic) mezclados de partículas nitrosas, sulfúreas, oleaginosas, que, volviendo a buscar el centro de la tierra, convertidas ya en unas malignas gotas por infrigidación (sic) del aire superior, esterilizarán campos y abrasarán las sementeras, dejando a los hombres con la malignidad de su respiración y pestíferos eructos de sus bostezos, expuestos a catarros, dolores pleuríticos y profluvios de vientre; enfermedades que padecieron los de Lima después de los grandes terremotos que se sintieron a 20 de octubre de $6877^{\prime 36}$

Como puede comprobarse, el terremoto despierta temores ancestrales a que una boca terrible se abra y lance su fétido aliento y haga llover sobre la tierra "gotas malignas" que, según dice este mismo autor más adelante, pueden llegar a favorecer la producción de "sabandijas" y demás animales repugnantes. ${ }^{37}$ Otro autor contemporáneo de Llano Zapata, el colegial de San Martín, Francisco Ruiz Cano y Galiano, llegó a establecer ciertas connotaciones mágico-religiosas entre la ruina de los templos y la infertilidad de los campos. En la obra que este personaje dedicó a la reconstrucción de la catedral de Lima, recordaba que, mientras estuvo caído el templo de Jerusalén, los campos de Judea no dieron fruto y que por ello la restauración del templo mayor limeño significaría también el fin de la esterilidad de las tierras..$^{38}$

Pero la realidad de 1746 fue que, a pesar de todos los temores, la producción de trigo, que ya por entonces se había recuperado, no se vio en absoluto afectada por el nuevo seísmo y en las cosechas siguientes se llegaron a recoger 50.000 fanegas anuales, que venía a ser la mitad de las más altas cotas de producción alcanzadas antes de la crisis de 1692. ${ }^{39}$ Esta era una situación muy poco conveniente para los navieros y los panaderos limeños, que desde hacía más de cincuenta años estaban haciendo magníficos negocios con la importación del trigo chileno. Ellos debieron ver en la llegada del nuevo seísmo una ocasión excepcional para renovar los ancestrales temores de los habitantes de la capital, recordándoles que los terremotos emponzoñaban los campos y que, por lo tanto, su salud dependía de consumir el trigo importado.

36 Llano Zapata, J.E.: Carta o diario que escribe don José de Llano y Zapata a su más venerado amigo y docto correspondiente el dr. don Ignacio Quiroga y Daza...en que...le da cuenta de todo lo acaecido en esta capital del Perú desde el viernes 28 de octubre que experimentó su mayor ruina..., Madrid, 1748, págs. 7-8.

37 Ibídem, pág. 14.

38 Ruiz Cano y Galiano, F.A.: Jubilos de Lima en la dedicación de su Santa Iglesia Catedral..., Lima, 1755, folios 148 vuelto-150 recto.

39 Bravo de Lagunas y Castilla: Voto consultivo..., pág. 11. 
En resumidas cuentas, la hipótesis que propongo para explicar la creación de un mito tan persistente se apoyaría en tres pilares básicos:

En primer lugar y debido a las explicaciones sismológicas del momento, desde las mentes más lúcidas del virreinato, hasta las creencias populares, admitían la posibilidad de que los movimientos sísmicos podían tener efectos secundarios que provocaban enfermedades tanto en las personas como en los animales y plantas.

En segundo lugar, existían en Lima poderosísimos intereses económicos interesados en desprestigiar la producción triguera local.

En tercer lugar, el tiempo transcurrido desde que en 1687 se produjo el anterior gran terremoto, facilitaba el que no existiese una clara conciencia del orden en que entonces se sucedieron los acontecimientos y resultó muy sencillo vincular dos sucesos (el movimientos sísmico de 1687 y la crisis agrícola iniciada en 1692), que en realidad estuvieron separados por cinco años, algunos de los cuales fueron de excelentes cosechas. En ese sentido, aunque la idea de responsabilizar al seísmo de 1687 de la esterilidad de los campos se había formulado en las primeras décadas del siglo XVIII, se vería reforzada tras la gran catástrofe telúrica de 1746.

Esta hipótesis se muestra especialmente plausible si tenemos en cuenta la rudeza y acritud de la disputa que, a mediados del siglo XVIII, ensarzaba en el virreinato a partidarios del trigo local ("criollo" era el termino usado entonces) y del chileno. Dos personajes de enorme influencia en la sociedad limeña pueden considerarse como adalides de ambas posturas. Nos referimos al oidor don Pedro José Bravo de Lagunas y Castilla y al decimotercer arzobispo de Lima, don Pedro Antonio de Barroeta y Ángel.

Bravo de Lagunas y Castilla era una figura clave en la vida política y social del virreinato. Como oidor decano de la Audiencia se había ganado la confianza del virrey don José Antonio Manso, que le había encargado importantes comisiones ejecutivas, desde la inspección de los edificios de la ciudad tras el terremoto, hasta la presidencia de la junta que estableció el estanco del tabaco, pasando por la investigación y castigo de los indígenas del Cercado que en 1750 intentaron asesinar al virrey y a todos los blancos..$^{40}$ Confirmando su papel de ser uno de los consejeros más importantes del virrey, Bravo de Lagunas dirigió a la suprema autoridad del

40 AGI, Lima, 985. Defensa de la política y de los asesores del virrey don José Antonio Manso de Velasco. Documento anónimo, fechado en Lima el 24 de abril de 1754. Sobre Bravo de Lagunas véase también Lohmann Villena, G.: Los ministros de la Audiencia de Lima (1700-1821), Sevilla, 1974, págs. 17-18. 
virreinato un larguísimo memorial que denomino: Voto consultivo, y que estaba destinado a demostrar la conveniencia de recuperar el cultivo de trigo criollo y terminar con las importaciones de Chile. ${ }^{41}$

En realidad, al virrey no hacía falta convencerlo de la bondad de esta idea, pues en su condición de viejo profesional de las armas, consideraba que depender de un abastecimiento exterior por vía marítima significaba una debilidad estratégica, en el caso de que, como había pasado otras veces, las incursiones inglesas en el Mar del Sur llegaran a cortar las líneas de comunicación y cerrasen los puertos. ${ }^{42}$

El Voto consultivo es un interesante ejemplo de las ideas fisiocráticas, pero es también de una enorme importancia para el tema que nos ocupa en estos momentos. En primer lugar, de su lectura se desprende que incluso las personas interesadas en luchar por el mantenimiento del trigo local admitían la posibilidad de que los terremotos fueran capaces de esterilizar los campos.

En efecto, Bravo de Lagunas está convencido que el seísmo de 1687 fue responsable de la ruina del trigo ocurrida en los años siguientes, aunque estimaba que estos episodios de esterilización de los campos eran desgracias que seguían sólo a algunos movimientos sísmicos, pero no a todos, tal y como se había podido ver por la nula repercusión que tuvo el de 1746 sobre la agricultura local. Las razones que, según el oidor, explican este caprichoso comportamiento de los terremotos permiten comprobar que los sesudos juristas de mediados del siglo XVIII también temían los malignos influjos de las influencias astrales. Así, don Pedro José estimaba que la causa de la tremenda malignidad del terremoto de 1687 se debió a que fue provocado por la conjunción de tres planetas: el poderoso Júpiter, el "tétrico Saturno" y el "ardiente Marte". Por el contrario, en el de 1746 faltó la alineación de este último, razón que, a su entender, justificaba el que en esa ocasión la naturaleza se conformara tan solo con derribar las casas y tragarse de un sorbo el puerto del Callao, pero dejara en paz los trigales y cañaverales de los valles limeños.

Pero Bravo de Lagunas nos proporciona unas informaciones aun más importantes para comprender la creación del mito del terremoto. El oidor indica que había en Lima muchas personas que, dejándose llevar más por

41 Bravo de Lagunas y Castilla: Voto consultivo... He manejado la segunda edición de esta obra, realizada en la imprenta de los Huerfanos de Lima en 1761, uno de cuyos ejemplares se encuentra en la colección de libros antiguos del AGI.

42 Manso de Velasco: Relación que escribe el conde de Superunda..., pág. 128. 
sus intereses económicos que por su sentido patriótico, estaban esparciendo calumnias contra la feracidad del suelo patrio. Don Pedro José llega a decir que se ha visto obligado a escribir el Voto consultivo, “...porque se conozca el poco aprecio que merece la voz que esparcen los que susurran la mala calidad del trigo criollo y que se mueven por su propio interés...". ${ }^{43}$ Y que su principal misión era luchar contra la "...miserable dependencia..." ${ }^{44}$ de Perú con respecto a Chile y contra el descrédito que estas falsedades estaban produciendo: “...yo no se por qué a esta tierra la desacreditan los que le deben el ser y la fortuna y con una especie de ingratitud ocultan su bondad....". ${ }^{45}$

El oidor no parece tener duda de quiénes eran los responsables de las calumnias: en primer lugar, los poderosos comerciantes y navieros que obtenían enormes beneficios con los fletes y la especulación, ya que guardaban el trigo en los almacenes y bodegas de su propiedad hasta que alcanzase un alto precio o lo ofrecían muy barato para arruinar a los hacendados locales. En segundo lugar, estaba el numeroso gremio de los panaderos, los cuales fingían despreciar el trigo local, pues según ellos proporcionaba “...poca harina y hace mal pan...”, pero, después, lo compraban en secreto a bajo precio y amasaban pan que vendían como si fuese hecho con trigo chileno de la mejor calidad. ${ }^{46}$

No es probable que Su Ilustrísima, el arzobispo don Pedro Antonio Barroeta y Ángel, fuera uno de esos difamadores que iban lanzando infundios ecológicos contra el trigo criollo, pero lo cierto es que se puso decididamente de parte de los importadores del cereal chileno. Estaba claro que si el virrey don José Antonio Manso y el oidor don Pedro José Bravo de Lagunas estaban en un bando, él iba a estar en el contrario.

La extrema rivalidad existente entre las máximas autoridades del virreinato no era un secreto para nadie. El arzobispo había tachado a los principales colaboradores del virrey, entre los que se contaba Bravo de Lagunas, de ser unos "mandarines odiados", una auténtica "pandilla" que practicaba todo tipo de cohechos y corruptelas ${ }^{47}$ No contento con eso, $\mathrm{Su}$ Ilustrísima había entrado en cuestiones personales, enviando al rey toda

43 Bravo de Lagunas y Castilla: Voto consultivo..., pág. 165.

44 Ibídem, pág. 23.

45 Ibídem, pág. 210.

46 Ibídem, pág. 4.

47 AGI, Lima, 985. El arzobispo de Lima al rey, Lima, 17 de enero de 1754. En este mismo legajo hay otras muchas misivas que prueban la inquina existente entre el arzobispo y las principales autoridades civiles del virreinato. 
una serie de acusaciones contra los usos privados de sus enemigos, informando, incluso, de las enfermedades consideradas vergonzosas que aquejaban a algunos de sus oponentes. De Bravo de Lagunas, concretamente, había comentado su excesiva afición por las jovencitas zambas, especialmente por dos hermanas que habían sido sucesivamente sus amantes y a las cuales tenía discretamente escondidas entre las criadas de un convento, enviándoles cada noche un coche para traerlas a su casa. ${ }^{48}$

Las relaciones de Barroeta con el Cabildo Eclesiástico no eran mejores que las que mantenía con el virrey y sus consejeros. Por ello, cuando los canónigos, que obtenían sus mayores rentas de los diezmos agrícolas, se decantaron por la defensa del trigo criollo, el arzobispo debió reforzarse en la idea de que la mejor postura era apoyar la importación de cereales. En el fondo, esta polémica constituía un excelente campo de batalla en el que enfrentarse a sus enemigos y tratar de infringirles una derrota significativa.

El arzobispo se convirtió por ello en uno de los más firmes opositores a la política que estaba siguiendo el virrey de dar preferencia de venta al trigo local sobre el importado. ${ }^{49}$ Barroeta, que hasta el momento no había sido un prelado muy popular, pretendió teñir de populismo su defensa del trigo foráneo, convirtiéndose en defensor de todos los consumidores y de los panaderos que estaban siendo castigados por incumplir las providencias del gobierno virreinal. Según el arzobispo, forzar a los limeños a comer pan amasado con grano criollo era lo mismo que "...obligar a comer pan caro, de inferior calidad [y] nocivo a la salud...". ${ }^{50} \mathrm{Al}$ mismo tiempo, las medidas para hacer efectiva la preferencia de los granos locales fueron presentadas como una auténtica extorsión contra los propietarios de las panaderías:

"No han sido atendidos, antes bien, han obligado a algunos de los panaderos a dejar este oficio y a otros les han derramado el trigo en los patios de sus casas, agregándose a estas injustas providencias las de prisión y otras consiguientes, al alterar a estas personas y obligarles a que no sólo tomen sin repugnancia alguna el dicho trigo [local], sino es también a que publiquen ser de mejor calidad que el trigo de Chile, cómo así lo han conseguido y dicen los panaderos, so pena de que serán perseguidos y castigados". ${ }^{51}$

48 AGI, Lima, 524. El arzobispo de Lima al rey, Lima, 15 de septiembre de 1755.

49 Manso de Velasco: Relación que escribe el conde de Superunda..., pág 128. El virrey informaba en su memoria de gobierno que había concedido a los labradores locales "prelación" a la hora de vender su grano. Demetrio Ramos se refiere al "preferentismo" del virrey Superunda y a la reacción que esta política desató en amplios sectores de la población: Ramos Pérez: Trigo chileno..., págs. 111-122.

50 AGI, Lima, 986. El arzobispo de Lima al rey, Lima, 26 de febrero de 1756.

51 Ibídem. 
Como vemos, la batalla por el abastecimiento de trigo a la población de Lima formaba parte de una auténtica guerra. Estaban en juego centenares de miles de pesos, y ganarla o perderla podía significar para muchos la diferencia entre la riqueza y la pobreza, entre el poder o la cárcel. La cuestión se veía complicada al teñirse de un evidente sentimentalismo de carácter patriótico y propiciaba que los diferentes grupos de poder político y religioso lo tomasen como bandera para dirimir sus antiguas y profundas disensiones. Por todo ello, creo que es una hipótesis muy razonable proponer que dentro de esta lucha generalizada, cualquier arma era buena para arrojársela al enemigo. En ese sentido, la calumnia ecológico-geográfica de que los terremotos emponzoñaban los campos constituía, y nunca mejor dicho, un dardo envenenado.

Cabe preguntarse por qué lo defensores del trigo local se dejaron ganar esta batalla propagandística y más teniendo en cuenta que, tras el violento seísmo de 1746, los hechos estaban mostrando que los campos cercanos a Lima no habían sufrido ningún tipo de esterilidad. Es posible que pueda haber influido, como hemos comentado, la preexistente idea de la malignidad casi diabólica de este tipo de fenómenos, lo cual hacía temer la multiplicación de las consecuencias catastróficas. Téngase en cuenta que, aun en la Lima ilustrada de mediados del siglo XVIII, la casi totalidad de la población seguía viendo los seísmos como un castigo de Dios por sus pecados y, en ese sentido, el concepto de "plaga bíblica", que tanto mata primogénitos, como envenena los campos, estaba siempre presente como una auténtica espada de Damocles..$^{52}$

También puede argumentarse que, simplemente, los defensores de la importación de trigo eran más poderosos económicamente y estaban más organizados que sus contrarios. ${ }^{53}$ En ese sentido, aunque el trigo local fuera defendido por el virrey, alguno de los oidores, los canónigos y los hacendados, tenían enfrente a los comerciantes y navieros que, en este caso, contaron con el apoyo de la mayoría de los consumidores, los cuales, por precio y calidad, preferían el pan hecho con trigo chileno.

$$
* * *
$$

52 Sobre la interpretación que los limeños hicieron del temblor de 1746 puede consultarse Llano Zapata: Carta o diario..., pág. 4 y siguientes.

53 En este sentido, Flores Galindo afirma que, a mediados del siglo XVIII, Lima era una ciudad dominada por los grandes comerciantes. Flores Galindo: La ciudad sumergida..., págs. 46 y 69. 
Queda reflexionar sobre por qué los historiadores que han estudiado esta cuestión se han dejado seducir tan mayoritariamente por el mito del terremoto envenenador. Es posible que todo proceda de la necesidad pedagógica que sentimos muchos profesionales de la historia por poner límites y fronteras precisas al fluir de los acontecimientos, al mismo tiempo que proponer explicaciones sencillas y claras a sucesos que, normalmente, resultan demasiado intrincados y complejos.

En ese sentido, las últimas décadas del siglo XVII en el Perú colonial constituyen, o han querido ser presentadas, como una especie de frontera, entre real y psicológica, que separaba una era brillante de su inevitable decadencia.

Curiosamente, si analizamos la correspondencia de las autoridades limeñas tras el terremoto de 1746 , todas coinciden en señalar que a mediados del siglo XVIII el virreinato se encontraba en peores condiciones que en 1687 para afrontar las tareas de reconstrucción. El virrey conde de Superunda afirmaba que en aquellos momentos era imposible conceder exenciones tributarias, tal y como se había hecho en 1687, ya que "...entonces [1687], estaba este reino muy florido y abundante de caudales.... ${ }^{54}$ De igual opinión eran los oficiales reales que hacían relatar "...la diversidad de los tiempos, pues entonces [1687], la Real Hacienda, no sólo no sufría menos pensiones en que estaba gravada, sino que se hallaba en disposición de hacer cuantiosas remesas a Su Majestad...". ${ }^{55}$ Incluso una institución privada, como el poderoso Consulado de Comercio, reconocía que los tiempos del virrey duque de la Palata, que era quien gobernaba el Perú en 1687, constituían un tiempo todavía "florido." ${ }_{6}$

Aun reconociendo que los afectados por una catástrofe en 1746 exageraban la cuantía de sus daños y lo penoso de su situación, no hay duda que a nivel de la imaginación popular existía la idea de que los tiempos del virreinato del duque de la Palata fueron "el canto de cisne" de la grandeza del Perú colonial y, si no una auténtica "Edad de Oro" como la primera mitad del siglo, tal vez podían constituir una "Edad de Plata" anterior al prolongado ocaso. En ese sentido, Ricardo Palma puede servirnos de testigo al recoger en sus Tradiciones peruanas que el duque de la Palata fue el "...virrey más virrey que el Perú tuvo...”, el cual, después de ser recibido con toda pompa, llegó a su palacio por un camino pavimentado por los comerciantes

54 AGI, Lima, 416. El virrey del Perú al rey, Lima, 16 de marzo de 1747.

55 Ibídem. Informe de los oficiales reales de la Caja de Lima. Lima, 19 de noviembre de 1746.

56 Ibídem. El Consulado de Comercio de Lima al rey, Lima, 17 de noviembre de 1746. 
con barretones de plata e, instalado en él, “...desplegó el lujo de un pequeño monarca, implantó la etiqueta y el refinamiento de una corte...". ${ }^{57}$

Tras estos últimos estertores de esplendor, pareció que todas las furias se desencadenaban contra el virreinato: las contantes entradas de piratas a través del istmo de Panamá; las dificultades crecientes para mantener el sistema de galeones con la metrópolis; el continuado descenso demográfico de la población indígena en general y de la mitaya en particular; los problemas crecientes de la producción argentífera y, finalmente, el terremoto de 1687 y la ruina de la agricultura costeña. El destino parecía confabularse contra la que había sido la joya más preciosa de la monarquía española en América y para que no falte el símbolo más importante: en los años 80 del siglo XVII, la producción de plata de las minas mexicanas alcanzó a las del Perú y, a partir de ese momento, la diferencia a favor de la Nueva España no hizo sino crecer de forma exponencial, superando al Perú a todo lo largo de la centuria siguiente. ${ }^{58}$

Para desentrañar convenientemente estos cambios y la subsiguiente decadencia del virreinato del Perú, los historiadores hemos hecho muchos esfuerzos y, como es natural, se han buscado el mayor número posible de vías para analizar de una manera satisfactoria y contundente un complejo problema como es éste. Por ello es claramente comprensible que se haya recurrido, entre otras, a una explicación sencilla, entendible por todo el mundo y que, además, exime de responsabilidades a los seres humanos y por lo tanto resulta muy conveniente para justificar sucesos desagradables. Me refiero, evidentemente, a achacar los fracasos humanos a los desastres naturales. Así, lo mismo que los barcos de la Armada de Felipe II se vieron tragados por los temporales en su empeño por invadir Inglaterra, el brillo del virreinato peruano se empañó enterrado por violentas sacudidas sísmicas.

Este tipo de explicaciones suelen ser, como es fácil de comprender, muy incompletas y poco satisfactorias. Creo que puede afirmarse con rotundidad que en el complejo drama de la decadencia del Perú, los terremotos, a pesar del rastro de destrucción que dejaron, no ocupan un papel protagonista, sino tan solo el de dramáticas comparsas. De esta manera, el viejo mito del seísmo que envenena las cosechas y esteriliza los campos sería en el siglo XVIII producto de una calumnia interesada y a lo largo de los siglos XIX y XX el resultado de unos intentos de explicación poco fundamentados.

57 Palma: Tradiciones peruanas..., págs. 464-465.

58 Según un artículo ya clásico, a fines de la década de los ochenta, la producción argentífera de México y el Perú se igualaron en 5 millones de pesos. Brading, D.A. y H.E, Cross: "Colonial Silver Minig: Mexico and Peru”, Hispanic American Historical Review, volumen LII, nº 4, 1972, págs. 545-579. 